\title{
Prevalence of arrhythmias in heavy vehicle drivers
}

\author{
Levent Özdemir $^{1 *}$, Okan Onur Turgut ${ }^{2}$, Ferhan Candan ${ }^{3}$, Seher Arslan ${ }^{1}$ \\ ${ }^{1}$ Cumhuriyet University, Faculty of Medicine, Department of Public Health, Sivas, Turkey \\ ${ }^{2}$ Cumhuriyet University, Faculty of Medicine, Department of Cardiology, Sivas, Turkey \\ ${ }^{3}$ Cumhuriyet University, Faculty of Medicine, Department of Nephrology, Sivas, Turkey \\ Email: ${ }^{\text {lozdem99@yahoo.com }}$
}

Received 2 October 2012; revised 10 November 2012; accepted 30 November 2012

\begin{abstract}
Objective: In our study we aimed to determine the frequency of arrhythmias that we believe may affect driving safety. Methods and Results: Two hundred drivers were randomly selected from the heavy vehicle driver population (82 bus and 118 truck drivers, $p$ $=0.08, \mathrm{q}=0.92, \mathrm{~N}=1200, \alpha=0.01, \mathrm{~d}=0.045)$. $\mathrm{A}$ questionnaire was completed via face to face interviews with the individuals including questions about their personal socio-demographic characteristics and symptoms for arrhythmias. An electrocardiography (ECG) was taken of the study participants using the Cardioline Delta 3 Plus Digital ECG machine. The cardiologist at the clinic evaluated the questionnaire and ECG for presence of arrhythmias. When indicated, ambulatory electrocardiography (Holter Monitoring) was performed for 24 hours in 133 individuals (71 drivers and 62 control). In cases that had Holter examination; ventricular ectopy was identified in $25.4 \%$ and $22.6 \%$, and supra-ventricular ectopy in $45.1 \%$ and $35.5 \%$ in the driver and the control groups; respectively. Ventricular tachycardia was detected in 2 patients. Arrhythmia frequencies were $59.1 \%, 54.8 \%$ and $57.1 \%$ in drivers, control and both groups respectively. Statistical differences between drivers and control group for rhythm disorders were not detected. Conclusions: Arrhythmias with lethal and devastating potential; need to be diagnosed and treated in professional drivers with extreme caution. The follow up and screening for heart diseases has a crucial role in preventing accidents and occupational diseases in drivers.
\end{abstract}

Keywords: Arrhythmia; Supra-Ventricular Ectopy; Ventricular Ectopy; Drivers; Prevalence

\section{INTRODUCTION}

Arrhythmias (or dysrhythmias) are problems that affect

"Corresponding author. the electrical system of the heart muscle, producing abnormal heart rhythms. The prevalence of atrial and ventricular arrhythmias tend to increase with age, even when there's no overt sign of heart disease. Acquired heart disease is the most important factor making a person prone to arrhythmias. The main causes are atherosclerosis, high blood pressure and inflammatory or degenerative conditions. Many chemical agents may cause arrhythmias, sometimes with serious consequences. Known factors include high or low blood and tissue concentrations of a variety of minerals. Alcohol, cigarettes and recreational drugs can provoke arrhythmias. So can various cardiac medications. Even drugs used to treat an arrhythmia may cause another arrhythmia [1].

Most people with heart diseases are able to continue to drive. However this relies on the heart condition and presence of symptoms. Whether a heart rhythm problem will affect driving or not depends on the type of arrhythmia. For most people as long as their arrhythmia is well controlled, driving may continue. However one may need to stop driving if the abnormal heart rhythm has caused or is likely to cause incapacity (unable/inability to drive). Once the underlying cause has been identified and symptoms controlled for at least once month, the patient may continue driving again [2]. Patients with ventricular arrhythmias are often restricted from driving by their physicians for several months. Over the past few years, however, more data have become available suggesting that it is safe to drive within three months of their ventricular tachyarrhythmia [3].

This study was conducted to explore the current health condition of the drivers in terms of cardiac disease. Since the heavy burden caused to the drivers cardiac health may be effected and hence may cause traffic accidents and occupational disease which makes this a potentially life threatening condition. Significant information regarding the current status may add to literature and be a pivotal study for further investigations. Even law makers may give attention to the study for further arrangements in this field of occupation.

In our study we aimed to determine the frequency of arrhythmia that has potential to affect driving safety. 


\section{METHODS}

This cross-sectional type study was conducted between November 2004 and September 2006. The number of registered heavy vehicle drivers to Sivas Professional Driver Association is 1200 (492 bus and 708 truck drivers). A total of 200 male persons ( 82 bus and 118 truck drivers) were randomly selected from the heavy vehicle driver population $(\mathrm{p}=0.08, \mathrm{q}=0.92, \mathrm{~N}=1200, \alpha=0.01$, $\mathrm{d}=0.045$ ). Two hundred non-driver persons of the same age group constituted the control group. Ninety percent were reached for the sample. A total of 181 heavy vehicle drivers were included in the study (75 bus and 106 truck drivers). Drivers with a constant job were included into the study. We reached the drivers via Sivas Professional Driver Association registry and asked for their participation and given informed consent. Drivers in a firm were reached by going to their firms and given information about the study. The drivers that were working for themselves were asked by phone calls and their participation into the study were provided. The ones that were unwilling to participate and did not come to their appointments two times were excluded from the study. No other exclusion criteria were accepted other than these.

Working as a driver before, unemployment, students and retired persons were excluded from the control group. No professional driver was present in the control group. Two cases that were realized to be professional driver, eleven cases that did not come to their appointment and 8 cases that needed further investigations were excluded from the control group (Totally 179 persons).

The current study was approved by Cumhuriyet University Ethic Committee and participant's confidentiality was guaranteed and the cases were told to feel free to withdraw from the study without any consequences whatsoever.

This study was planned as two steps and on non-work day. First step was conducted in Department of Public Health, Faculty of Medicine Building (outside of hospital) Cumhuriyet University. A questionnaire was completed in face to face interviews with the individuals who were asked questions about their personal sociodemographic characteristics and symptoms for arrhythmia. The questions of the questionnaire were oriented to the cardiac history and possible symptoms in arrhythmias. The question were established by the cardiology fellows that participated in the study. However the questionnaire was not validated for detection of arrhythmias which was not a primary objective of the current study. An electrocardiography (ECG) was taken of the study participants using the Cardioline Delta 3 Plus Digital ECG machine.

In the second stage of the study, a patient file was created for every participant which included the questionnaire and ECG. An appointment was made for the patient at Cumhuriyet University Medical Faculty Teaching Hospital Cardiology Outpatient Clinic. The cardiologist at the clinic evaluated the questionnaire and ECG for arrhythmias and, when indicated, ambulatory electrocardiography (Holter Monitoring) was performed for 24 hours in 133 individuals ( 71 driver and 62 control). A Holter monitor is a portable device for continuously monitoring various electrical activity of the cardiovascular system for at least 24 hours. It is frequently used for detecting arrhythmias and for checking the success of the drugs or therapies to control the arrhythmias.

The data were entered into the computer using the SPSS program. Student's $t$ test and Chi square test were used in the statistical evaluation.

\section{RESULTS}

The mean age of the study participants was $40.32 \pm 8.58$ years. There was no significant difference between the study and control groups for mean age. The distributions of some of the risk factors for the study and control groups was given in Table $\mathbf{1}$.

Table 1. The distribution of some of the risk factors for the study and control groups.

\begin{tabular}{|c|c|c|c|c|}
\hline & \multicolumn{2}{|c|}{ Drivers } & \multicolumn{2}{|c|}{ Control } \\
\hline & $\mathrm{n}$ & $\%^{*}$ & $\mathrm{n}$ & $\%^{*}$ \\
\hline \multicolumn{5}{|c|}{ Blood Pressure, $\left(\chi^{2}=3.92, p<0.05\right)$} \\
\hline Hypertensive & 38 & 21.0 & 23 & 12.8 \\
\hline Normotensive & 143 & 79.0 & 156 & 87.2 \\
\hline \multicolumn{5}{|c|}{ Cigarette Status, $\left(\chi^{2}=3,63, p>0.05\right)$} \\
\hline Current Smokers & 114 & 63.0 & 95 & 53.1 \\
\hline Not current smokers & 67 & 27.6 & 84 & 41.3 \\
\hline \multicolumn{5}{|c|}{ Regularly Physical Activity, $\left(\chi^{2}=3.43, p>0.05\right)$} \\
\hline Yes & 25 & 13.8 & 38 & 21.8 \\
\hline No & 156 & 86.2 & 141 & 78.8 \\
\hline \multicolumn{5}{|c|}{ Body Mass Index, $\left(\chi^{2}=9.33, \mathrm{p}<0.05\right)$} \\
\hline Normal & 41 & 22.7 & 60 & 33.5 \\
\hline Overweight & 87 & 48.0 & 88 & 49.2 \\
\hline Obese & 53 & 29.3 & 31 & 17.3 \\
\hline \multicolumn{5}{|c|}{ Balanced Diet, $\left(\chi^{2}=0.45, \mathrm{p}>0.05\right)$} \\
\hline Yes & 105 & 58.0 & 111 & 62.0 \\
\hline No & 76 & 42.0 & 68 & 38.0 \\
\hline \multicolumn{5}{|c|}{ Family history of Cardiovascular Disease, $\left(\chi^{2}=5.67, \mathrm{p}<0.05\right)$} \\
\hline Yes & 35 & 19.3 & 54 & 30.2 \\
\hline No & 146 & 80.7 & 125 & 69.8 \\
\hline \multicolumn{5}{|c|}{ Alcohol Consumption, $\left(\chi^{2}=0.10 \mathrm{p}>0.05\right)$} \\
\hline Yes & 34 & 1.7 & 36 & 3.9 \\
\hline No & 147 & 81.2 & 143 & 79.9 \\
\hline
\end{tabular}


We evaluated the drivers for presence of cardiac risk factors. Among drivers $48.0 \%$ cases were were mildly obese and $29.3 \%$ were obese, compared to $49.2 \%$ and $17.3 \%$, respectively, for the control group $(\mathrm{p}<0.05)$. Blood pressure readings revealed presence of hypertension in $21.0 \%$ of the drivers and $12.8 \%$ of the control group $(\mathrm{p}<0.05)$. Fifth-eight percent of the drivers and $62.0 \%$ of the control group had a balanced diet $(p>0.05)$. The prevalence of a history of heart disease in a first degree relative in drivers and the control group were 19.3\% and $30.2 \%$; respectively $(p>0.05)$. The prevalence of cigarette smoking in the drivers and in the control group was $63.0 \%$ and $53.1 \%(\mathrm{p}<0.05)$. The majority of both the drivers $(81.2 \%)$ and the control groups $(79.9 \%)$ consumed no alcohol $(\mathrm{p}>0.05)$. The ECG of the cases were obtained. An example ECG of a case is given in Figure 1.

The distribution of answers to questions related to arrhythmia according to study and control group was given in Table 2.

The frequencies of feeling irregularities in heart rhythm were $36.5 \%$ and $31.3 \%$ while feeling pauses were $18.8 \%$ and $11.2 \%$ in the driver and control group; respectively. The frequencies of having acceleration in heart rhythm during rest were $21.5 \%$ and $19.0 \%$, while having deceleration were $16.0 \%$ and $6.7 \%$ in the driver and control groups; respectively.

24 hours of ambulatory electrocardiography monitoring was performed in 130 individuals (71 driver and 62 control). Means of basic rhythm parameters obtained from Holter monitoring according to driver and control group were given in Table 3 .

The prevalences of rhythm disorders was given in Table 4.

In the Holter study frequencies of having ventricular ectopy were $25.4 \%$ and $22.6 \%$, while having supra-ventricular ectopy were $45.1 \%$ and $35.5 \%$ in driver and control groups respectively. Ventricular tachycardia was detected in 2 patients with supra-ventricular ectopy. Overall frequencies of having some sort of arrhythmia were determined as $59.1 \%, 54.8 \%$ and $57.1 \%$ in drivers, control and both groups respectively. Statistical differences between drivers and control group for rhythm disorders were not detected.

In total, 360 people the prevalences of ventricular, supra ventricular and arrhythmia were identified as $8.9 \%$,

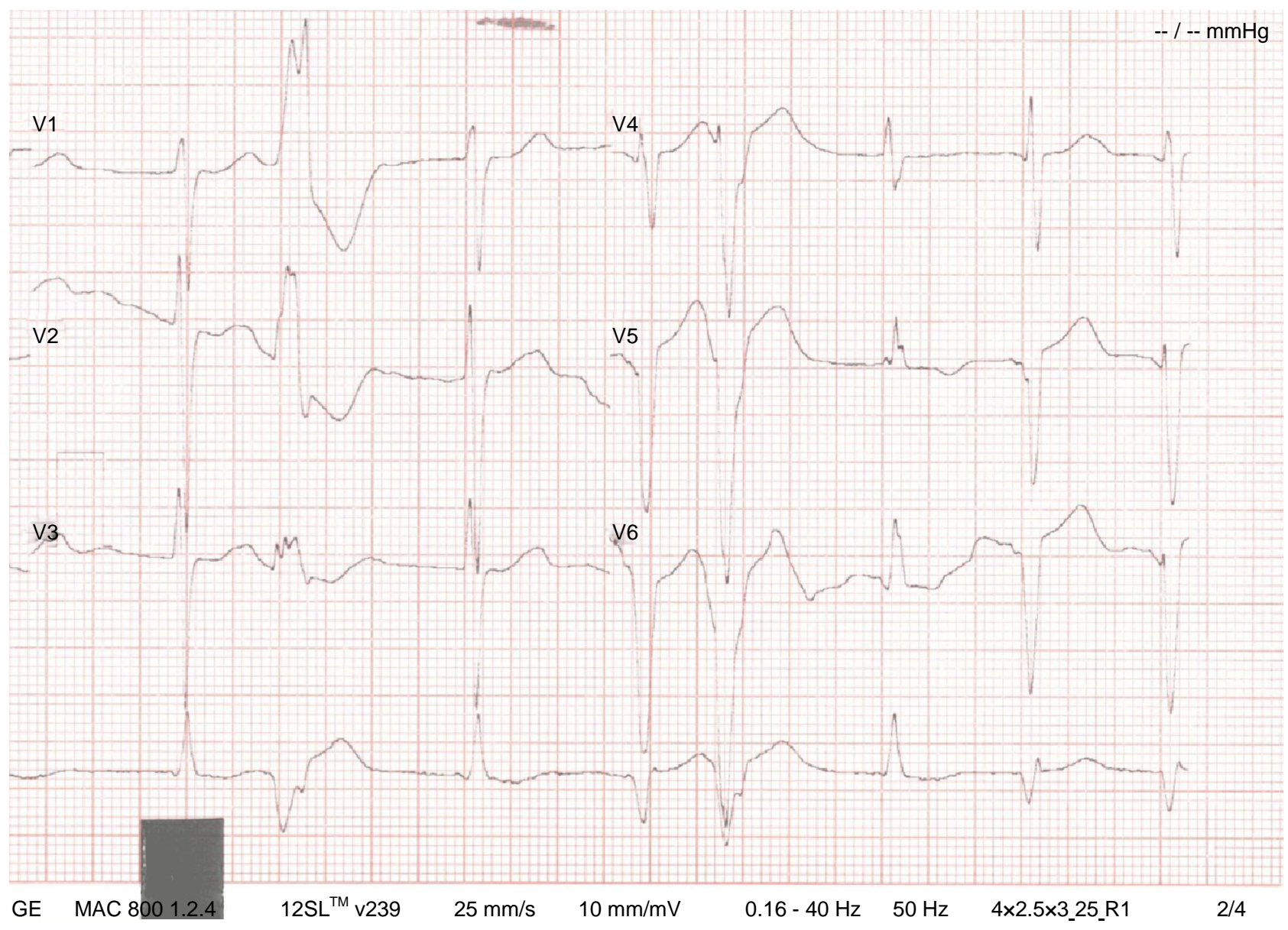

Figure 1. An ECG of a patient showing ventricular extrasystoles of different origins and aberrant conduction in some beats. 
Table 2. The distribution of answers to questions related to arrhythmia according to study and control group.

\begin{tabular}{|c|c|c|c|c|c|c|}
\hline & \multicolumn{2}{|c|}{ Drivers (181) } & \multicolumn{2}{|c|}{ Control (179) } & \multicolumn{2}{|c|}{ Total } \\
\hline & $\mathrm{n}$ & $\%$ & $\mathrm{n}$ & $\%$ & $\mathrm{n}$ & $\%$ \\
\hline \multicolumn{7}{|c|}{$\begin{array}{l}\text { Have you ever felt an irregularity in your heartbeat? }\left(\chi^{2}=1.08, \mathrm{p}\right. \\
\qquad>0.05)\end{array}$} \\
\hline Yes & 66 & 36.5 & 56 & 31.3 & 122 & 33.9 \\
\hline No & 115 & 63.5 & 123 & 68.7 & 238 & 66.1 \\
\hline \multicolumn{7}{|c|}{ Have you ever fainted? $\left(\chi^{2}=3.19, p>0.05\right)$} \\
\hline Yes & 10 & 5.5 & 19 & 10.6 & 29 & 8.1 \\
\hline No & 171 & 94.5 & 160 & 89.4 & 331 & 91.9 \\
\hline
\end{tabular}

Have you ever felt a chest pain with palpitations? $\left(\chi^{2}=1.42 \mathrm{p}>\right.$ $0.05)$

$\begin{array}{ccccccc}\text { Yes } & 36 & 19.9 & 45 & 25.1 & 81 & 22.5 \\ \text { No } & 145 & 80.1 & 134 & 74.9 & 279 & 77.5\end{array}$

Have you ever felt an acceleration in your heartbeat rest in case? $\left(\chi^{2}=0.36, p>0.05\right)$

$\begin{array}{ccccccc}\text { Yes } & 39 & 21.5 & 34 & 19.0 & 73 & 20.3 \\ \text { No } & 142 & 78.5 & 145 & 81.0 & 287 & 79.7\end{array}$

Have you ever felt a deceleration in your heartbeat rest in case? $\left(\chi^{2}=7.74, \mathrm{p}<0.05\right)$

$\begin{array}{ccccccc}\text { Yes } & 29 & 16.0 & 12 & 6.7 & 41 & 11.4 \\ \text { No } & 152 & 84.0 & 167 & 93.3 & 319 & 88.6\end{array}$

Have you ever felt a pause in your heartbeat? $\left(\chi^{2}=4.09, \mathrm{p}<0.05\right)$

\begin{tabular}{ccccccc} 
Yes & 34 & 18.8 & 20 & 11.2 & 54 & 15.0 \\
No & 147 & 81.2 & 159 & 88.8 & 306 & 85.0 \\
\hline
\end{tabular}

$16.4 \%$ and $21.1 \%$ respectively.

\section{DISCUSSION}

Patients with arrhythmias may experience complete or partial loss of consciousness, and questions about activities that are safe for them arise every day. Experience in Europe also suggests that the impact of arrhythmia-induced loss of consciousness is a relatively minor factor in road accidents. Approximately $0.1 \%$ of reported road accidents are attributed to medical causes, and only $10 \%$ to $25 \%$ of these are due to cardiac events [4]. Among 3000 cases surveyed from the records of the Medical Control Unit of the Virginia Commonwealth Department of Motor Vehicles, only 6\% were deemed related to cardiovascular disease, and of these, only a fraction (14\%) appeared to be associated with cardiac arrhythmias [5].

Rigou et al. determined that $43.4 \%$ of university students had ventricular arrhythmias (12 males and $18 \mathrm{fe}-$ males) [6]. In a study conducted by Gogolashvili et al. in Krasnoiarsk region the prevalences of supraventricular

Table 3. Means of basic rhythm parameters.

\begin{tabular}{cccc}
\hline & Driver $(\mathrm{n}=71)$ & Control $(\mathrm{n}=62)$ & $\mathrm{p}$ value \\
\cline { 2 - 3 } & $\mathrm{X} \pm \mathrm{SE}$ & $\mathrm{X} \pm \mathrm{SE}$ & \\
\hline Basic Rhythm & & & \\
Average rate & $75.59 \pm 1.18$ & $77.43 \pm 2.76$ & $\mathrm{p}>0.05$ \\
Minimum rate & $49.2 \pm 1.77$ & $50.07 \pm 2.69$ & $\mathrm{p}>0.05$ \\
Maximum rate & $128.74 \pm 3.01$ & $129.86 \pm 3.98$ & $\mathrm{p}>0.05$ \\
\hline
\end{tabular}

Table 4. The frequencies of rhythm disorders for driver and control group according to Holter monitoring.

\begin{tabular}{|c|c|c|c|c|c|c|}
\hline \multirow[t]{2}{*}{ Holter applied individuals } & \multicolumn{2}{|c|}{ Drivers (71) } & \multicolumn{2}{|c|}{ Control (62) } & \multicolumn{2}{|c|}{ Total (133) } \\
\hline & $\mathbf{n}$ & $\%{ }^{*}$ & $\mathbf{n}$ & $\%^{*}$ & $\mathbf{n}$ & $\%^{*}$ \\
\hline $\operatorname{VE}\left(\chi^{2}=0.03, \mathrm{p}>0.05\right)$ & 18 & 25.4 & 14 & 22.6 & 32 & 24.0 \\
\hline $\operatorname{SVE}\left(\chi^{2}=0.9, \mathrm{p}>0.05\right)$ & 32 & 45.1 & 22 & 35.5 & 59 & 44.4 \\
\hline $\mathrm{VE}+\operatorname{SVE}\left(\chi^{2}=2.03, \mathrm{p}>0.05\right)$ & 8 & 11.3 & 2 & 3.3 & 10 & 7.5 \\
\hline Ventricular tachycardia $\left(\chi^{2}=0.04, \mathrm{p}>0.05\right)$ & 2 & 2.8 & - & - & 2 & 1.5 \\
\hline Any kind of arrhythmia $\left(\chi^{2}=0.11, \mathrm{p}>0.05\right)$ & 42 & 59.1 & 34 & 54.8 & 76 & 57.1 \\
\hline \multirow[t]{2}{*}{ Whole individuals } & \multicolumn{2}{|c|}{ Drivers (181) } & \multicolumn{2}{|c|}{ Control (179) } & \multicolumn{2}{|c|}{ Total (360) } \\
\hline & $\mathbf{n}$ & $\%{ }^{*}$ & $\mathbf{n}$ & $\%{ }^{*}$ & $\mathbf{n}$ & $\%^{*}$ \\
\hline $\operatorname{VE}\left(\chi^{2}=0.27, \mathrm{p}>0.05\right)$ & 18 & 9.9 & 14 & 7.8 & 32 & 8.9 \\
\hline $\operatorname{SVE}\left(\chi^{2}=1.65, \mathrm{p}>0.05\right)$ & 32 & 17.7 & 22 & 12.3 & 59 & 16.4 \\
\hline $\mathrm{VE}+\operatorname{SVE}\left(\chi^{2}=2.51, \mathrm{p}>0.05\right)$ & 8 & 4.4 & 2 & 1.1 & 10 & 2.8 \\
\hline Ventricular tachycardia $\left(\chi^{2}=0.49, \mathrm{p}>0.05\right)$ & 2 & 1.1 & - & & 2 & 0.6 \\
\hline Any kind of arrhythmia $\left(\chi^{2}=0.72, \mathrm{p}>0.05\right)$ & 42 & 23.2 & 34 & 19.0 & 76 & 21.1 \\
\hline
\end{tabular}

*Column percent, VE: ventricular ectopy, SVE: supra ventricular ectopy. 
and ventricular ectopies were reported as in $56.7 \%$ and $34.4 \%$, respectively [7].

Komsuoğlu et al. in their study conducted in 130 elderly patients, reported that according to the Lown grades, in grade 1 , ventricular premature complexes had very high prevalence in healthy subjects, in grade 2, ventricular premature complexes had a high prevalence in hypertensives with left ventricular hypertrophy $(73.5 \%$ and $48.8 \%$, respectively). The results of his study demonstrated that ventricular premature complexes were common in hypertensive patients and healthy elderly but did not cause high complexity in either group. Ventricular premature complexes detected by ambulatory ECG monitoring in healthy, active subjects and in untreated hypertensive patients were not an independent risk factor in elderly patients in his study [8]. In a study by Engel and Burckhardt conducted in 35 healthy volunteers with a mean age of 24 years the prevalences for ventricular and supraventricular premature contractions were recorded occasionally in $31 \%$ and with greater frequency in $6 \%$ [9]. In a review by Paparella et al. the prevalences for supra-ventricular premature beats has been reported as in $10 \%-20 \%$ of subjects less than 20 years, in $30 \%-60 \%$ of those between 20 and 60 years, in $90 \%$ of subjects older than 75 years [10]. The frequency of having of one or more premature ventricular beats (PVBs) was reported as $61 \%$ by Rasmussen et al. [11]. In a study conducted by Turner et al. the arrhythmia prevalence was reported as $80 \%(13.5 \%$ ventricular, $38.4 \%$ supra-ventricular and $48.1 \%$ combined) [12]. In a study conducted by Adey et $a l$. in Burckhardt the frequencies of ventricular, supraventricular and combined ectopy were reported as $16 \%$, $10.5 \%$ and 10.5; respectively [13]. Hanne-Paparo et al. found a $6.2 \%$ prevalence for isolated atrial or ventricular premature contractions in athletes [14]. The prevalence of frequent than 1:10 premature beats was reported as $11 \%$ in Onat's study [15]. The prevalences of arrhythmias were higher than Adey, Hanne-Paparo and Onat's work while lower than the other studies in our study.

Researches related to the frequency of arrhythmias in different societies and groups have been made. We think our study may add to the current data in the literature about the topic.

\section{CONCLUSION}

Arrhythmias having lethal and devastating potential need careful examination and follow-up. Although the body mass index, family history cardiovascular disease and blood pressure were significantly different in heavy vehicle drivers compared to the control group these did not cause significant difference in terms of arrhythmias. Periodic health check-ups for heavy vehicle drivers would allow for the diagnosis of any heart disease at an early stage and the initiation of necessary treatment.

\section{REFERENCES}

[1] American Heart Association (2003) Heart and stroke facts.

http://www.americanheart.org/downloadable/heart/10567 19919740HSFacts2003text.pdf

[2] British Heart Foundation (2009) Driving. http://www.bhf.org.uk/living_with_a_heart_condition/rec overy/driving.aspx

[3] Bleakley, J.F. and Akiyama, T. (2003) Driving and arrhythmias: Implications of new data. Cardiac Electrophysiology Review, 7, 77-79. doi:10.1023/A:1023655410200

[4] Epstein, A.E., Miles, W.M., Benditt, D.G., Camm, A.J., Darling, E.J., Friedman, P.L., et al. (1996) Personal and public safety issues related to arrhythmias that may affect consciousness: Implications for regulation and physician recommendations: A medical/scientific statement from the American Heart Association and the North American Society of Pacing and Electrophysiology. Circulation, 94, 1147-1166. doi:10.1161/01.CIR.94.5.1147

[5] McCue, H. (1995) Cardiac arrhythmias in relation to automobile driving. Scientific Conference on Personal and Public Safety Issues Related to Arrhythmias, Washington, January 12-13 1995.

[6] Rigou, D.G., Pichel, G. and Fasah, L. (1990) Ventricular arrhythmia in young university students without evidence of heart disease. Medicina (Buenos Aires), 50, 47-51.

[7] Gogolashvili, N.G., Novgorodtseva, N.I., Polikarpov, L.S. and Karpov, R.S. (2004) Incidence of heart rate disorders in rural population of Krasnoiarsk region. Terapevticheskǐ̆ Arkhiv, 76, 41-44.

[8] Komsuoğlu, B., Duman, E., Komsuoğlu, S.S. and Görçin, B. (1993) Prevalence of ventricular premature complexes in healthy and untreated hypertensive elderly people. $\mathrm{An}$ giology, 44, 447-453. doi:10.1177/000331979304400604

[9] Engel, U.R. and Burckhardt, D. (1975) Frequency and form of arrhythmia and changes in ECG in juvenile healthy volunteers. Studies with long-term electrocardiography. Schweizerische Medizinische Wochenschrift, 105, 1467-1469.

[10] Paparella N. and Alboni P. (1991) Classification and prevalence of supraventricular tachyarrhythmia. Cardiología, 36, 7-10.

[11] Rasmussen, V., Jensen, G., Schnohr, P. and Hansen, J.F. (1985) Premature ventricular beats in healthy adult subjects 20 to 79 years of age. European Heart Journal, 6, 335-341.

[12] Turner, A.S., Watson, O.F., Adey, H.S., Cottle, L.P. and Spence, R. (1981) The prevalence of disturbance of cardiac rhythm in randomly selected New Zealand adults. The New Zealand Medical Journal, 93, 253-255.

[13] Adey, H., Ballantyne, D.A., Bostock, M.I., Fleischl, P., Kurta, A.V., Langley, R.B., et al. (1978) The prevalence of disturbance of cardiac rhythm in healthy New Zealand adults: A pilot study. The New Zealand Medical Journal, 88, 433-435. 
[14] Hanne-Paparo, N. and Kellermann, J.J. (1981) Long-term Holter ECG monitoring of athletes. Medicine \& Science in Sports \& Exercise, 13, 294-298. doi:10.1249/00005768-198105000-00004
[15] Onat, A., Avcı, G.Ş., Örnek, E. and Şenocak, M. (1993) Türk erişkinlerde elektrokardiyografik bulgular ile aritmilerin prevalansı: Bir epidemiyoloji çalışma. Türk Kardiyoloji Derneği Arşivi, 21, 11-16. 